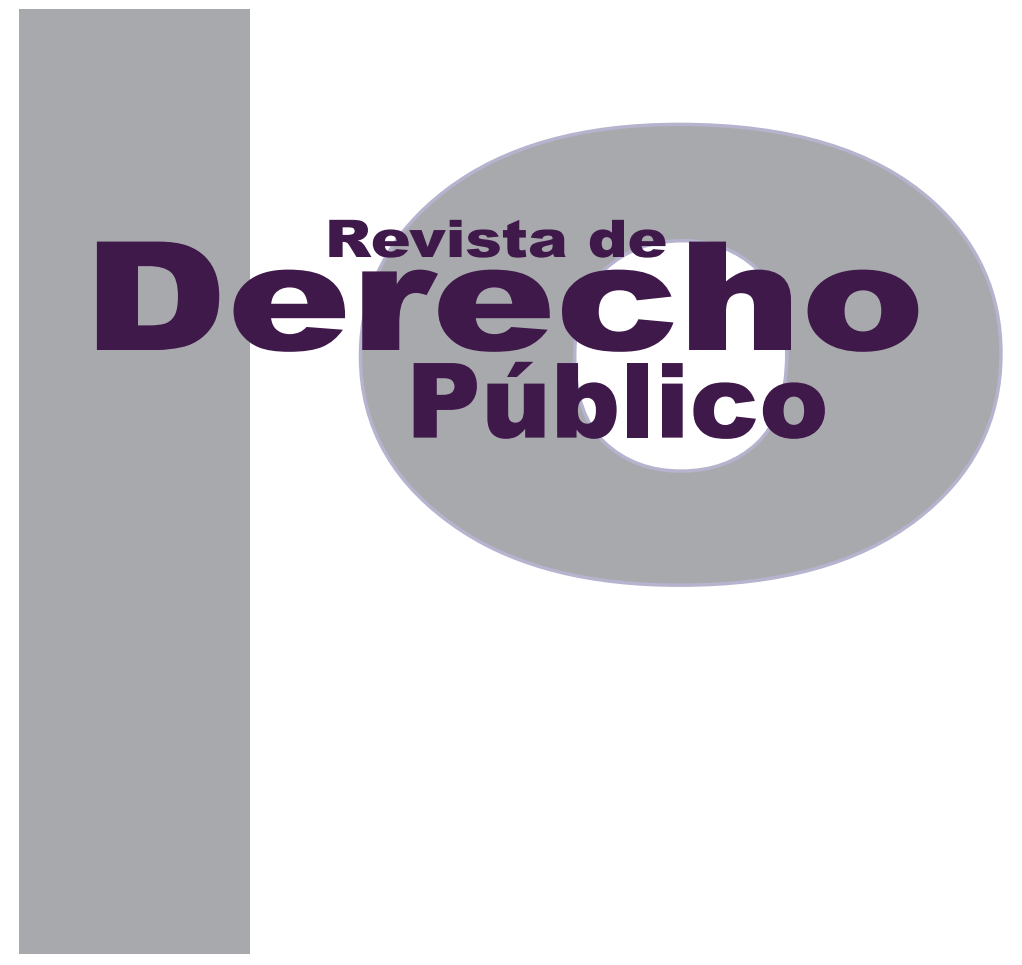

\title{
CONTRA LA INJUSTICIA: NOTAS SOBRE EL DISCURSO CONTRACONSTITUCIONAL LATINOAMERICANO
}

\author{
JosÉ MARÍA MonzóN \\ Artículo de reflexión \\ DOI: http://dx.doi.org/10.15425/redepub.33.2014.04 \\ Universidad de los Andes \\ Facultad de Derecho \\ Revista de Derecho Público N. ${ }^{\circ} 33$ \\ Julio - Diciembre de 2014. ISSN 1909-7778
}




\section{Contra la injusticia: notas sobre el discurso contraconstitucional latinoamericano}

\section{Resumen}

El presente trabajo - parte de una investigación mayor que tiene por objeto a la filosofía del colonialismo legal en Latinoamérica - tiene por finalidad examinar la relación entre indigenismo, democracia revolucionaria y discurso contraconstitucional en la época contemporánea en el contexto latinoamericano. La fuente principal es la literatura de ficción, porque es un relevante elemento de la cultura legal externa. Pero también se consideran las recientes reformas constitucionales de Bolivia y Ecuador. La metodología es exploratoria y desarrolla un análisis crítico de las fuentes primarias y secundarias. De acuerdo con las razones explicadas antes, los resultados son parciales, pero importantes para definir el colonialismo legal y describir los desafíos que este expone a la cultura legal latinoamericana.

Palabras clave: discurso contraconstitucional, derecho y literatura, movimientos sociales, indigenismo, Revolución Francesa, constitucionalismo latinoamericano.

\section{Against injustice: some keynotes on the counter-constitutional latin-american discourse}

\section{Abstract}

This paper - part of a major research which has as objective the philosophy of legal colonialism in Latin America- is dedicated to examine the relationship between indigenism, revolutionary democracy, and counter-constitutional discourse, within the contemporary age in the Latin American context. Our main source is fictional literature, for it is an important constituent of the external legal culture. But it also takes account of the recent constitutional reforms in Bolivia and Ecuador. The methodology is exploratory and it has a critical point of view of the primary and secondary sources. For the reasons explained above, the results are partial, though they are essential to define the legal colonialism and to describe the challenges they expounded to Latin America legal culture.

Keywords: counter-constitutional discourse, law and literature, social movements, indigenism, French Revolution, Latin American Constitutionalism.

\section{Contra a injustiça: notas sobre o discurso contra constitucional latino-americano}

\section{Resumo}

O presente trabalho - parte de uma pesquisa maior que tem por objeto a filosofia do colonialismo legal na América Latina- tem por finalidade examinar a relação entre indigenismo, democracia revolucionária e discurso contra constitucional na época contemporânea no contexto latino-americano. A principal fonte é a literatura de ficção, porque é um elemento relevante da cultura legal externa. Mas também se consideram as recentes reformas constitucionais da Bolívia e do Equador. A metodologia é exploratória e desenvolve uma análise crítica das fontes primárias e secundárias. De acordo com as razões explicadas antes, os resultados são parciais, mas importantes para definir o colonialismo legal e descrever os desafios que este expõe à cultura legal latino-americana.

Palavras-chave: discurso contra constitucional, direito e literatura, movimentos sociais, indigenismo, Revolução Francesa, constitucionalismo latino-americano. 


\title{
Contra la injusticia: notas sobre el discurso contraconstitucional latinoamericano*
}

\author{
José María Monzón**
}

\section{SUMARIO}

Introducción - I. LA CRÍTICA AL ORDEN CONSTITUCIONAL - II. EL DISCURSO CONTRACONSTITUCIONAL - A. Notas generales - B. Notas para caracterizar al discurso contraconstitucional - III. EL CAMINO HACIA LA DEMOCRACIA REVOLUCIONARIA - IV. ¿SON LAS NUEVAS CONSTITUCIONES LATINOAMERICANAS FRUTO DEL DISCURSO CONTRACONSTITUCIONAL? - V. CONCLUSIONES - Referencias.

* Cómo citar este artículo: Monzón, J. M. (Diciembre, 2014). Contra la injusticia. Notas sobre el discurso contraconstitucional latinoamericano. Revista de Derecho Público, 33. Universidad de los Andes (Colombia).

** Abogado (Pontificia Universidad Católica Argentina). Doctor en Derecho (Universidad Argentina John F. Kennedy). Profesor de Teoría General y Filosofía del Derecho (Facultad de Derecho de la Universidad de Buenos Aires). Investigador permanente del Instituto de Investigaciones Jurídicas y Sociales "Ambrosio L. Gioja" de la misma Facultad. Correo: monzonjm@derecho.uba.ar 
Introducción

Ciro Alegría relata en el prólogo a la vigésima edición de su libro El mundo es ancho y ajeno (1973) que al salir de una conferencia en la universidad, en Cuzco, su mujer le preguntó si había notado la presencia de un indio entre el público. Su respuesta fue que no. Pero al otro día, al salir del hotel, se le acercó quien había presenciado su conferencia. Se presentó como Juan Yaco y le comentó “Don Ciro, usted es un escritor del pueblo y le hago saber que nos está pasando igualito que en El mundo es ancho $y$ ajeno (la obra de Alegría)" (1973, p. 9). Este comentario deja ver que lo que Alegría había escrito no se alejaba de la realidad en la que vivían las comunidades indígenas, y era lo que el indígena que había escuchado a Alegría le había expresado. Si Yaco hubiese leído además a Jesús Lara o a Alcides Arguedas o a Jorge Icaza, su opinión hubiese sido la misma. Los relatos de estos escritores que describían la vida cotidiana de los indígenas y de sus comunidades con sus escenas de violencia y de sumisión, producto de las tensiones existentes entre los indígenas, los mestizos y los blancos, poco diferían de lo que realmente ellos vivían. En este sentido, las obras de estos escritores -Alegría, Lara, Alcides Arguedas, y otros ubicados en la misma línea narrativa- eran algo más que el fruto de su imaginación, sus novelas expusieron las situaciones que padecían las comunidades indígenas y, de esa manera, sirvieron para hacerlas conocer a los lectores locales. Si alguien hubiese querido entender por qué la reivindicación de los derechos de los indígenas se hizo desde el campo político de un modo tan violento, lo que narraron estos autores hubiera bastado para justificarlas.

Al vehiculizar las condiciones de vida de los indígenas esos textos sirvieron para argumentar en favor de la lucha por parte de los futuros movimientos indígenas, y para sumar adeptos más allá de estos grupos. Al revelar a los lectores lo que era el mundo no blanco, un mundo que les era - parafraseando a Alegría - ajeno, tanto como lo era el mundo de los blancos para los indígenas, las tramas de esas narraciones se tradujeron en semilla de cambios sociales profundos.

En este sentido, es posible sostener que esas obras sobrepasaron el espacio de la literatura, y a sus propios autores. Su contenido fue integrado a los discursos indigenistas latinoamericanos. Así se tendió un puente entre la literatura y la política, que también alcanzó al derecho, y más especialmente, al derecho constitucional. La razón esencial de este puente se comprende cuando se tiene en cuenta que -tradicionalmente- la construcción de la Constitución fue una tarea asignada usualmente a la academia legal y a los representantes políticos, dos colectivos integrados por individuos pertenecientes a las mismas clases sociales, de las cuales también provenían los escritores críticos del orden social dado. Lo que estos últimos criticaron a través de sus obras era lo que los indígenas pensaban que acontecía en la realidad, y que una transformación social significativa debía darse. En algún sentido, se puede decir que la emergencia de esta literatura tuvo efectos no previstos. ${ }^{1}$

Por ejemplo, Arguedas "murió con la conciencia de haber contribuido en gran medida al debate sobre la "cuestión del indio". Al denunciar los 
En primer lugar, esta literatura fue útil para dejar de lado la imagen romántica del indígena y, al mismo tiempo, las supuestas bondades del paternalismo del blanco. Segundo, se tomó nota de las reivindicaciones que los indígenas planteaban y que concernían básicamente al derecho al disfrute de los derechos reconocidos en las constituciones. Y por último, se empezó a valorar su cultura. Esto es lo que trajo consigo el surgimiento de la literatura denominada indigenismo o indianismo literario: el descubrimiento de la injusticia generalizada bajo la cual vivían las comunidades indígenas desde los tiempos de la conquista española, y que continuaron en la etapa de postindependencia.

En este contexto - tanto en el real como en el ficticio- brotan demandas que exceden lo legal, y explican las razones de la necesidad de realizar un cambio social radical que devuelva y reconozca los derechos que los indígenas poseen,

Como si todo el mundo no supiera que en este nuestro Perú hay cinco millones de indios que viven bajo la miseria y la explotación más espantosa. Lo que importa es que nosotros mismos nos convenzamos de que el problema existe y lo afrontemos en toda su realidad. De tanto querer engañar a los demás, estamos engañándonos a nosotros mismos... (Alegría, 1973, p. 454).

abusos de los terratenientes, habría, según su propia lectura, ayudado a sensibilizar a la élite terrateniente y al poder político con respecto a la situación del indio, y con ello impulsado las mejoras en su situación jurídica y laboral. Aunque es cierto que la novela fue un hito señero (...) es difícil estimar el grado de influencia de una obra literaria en los cambios que ocurren en la vida real" (Paz Soldán, 2006, p. 22).
Es lo que dice uno de los personajes de la novela de Alegría.

Al respecto se opina que el indigenismo literario, y buena parte de la narrativa latinoamericana, no tiene un objeto autónomo, cerrado en sí mismo. Porque su función va más allá de su valor estético para adquirir una dimensión política. Más bien, su función es intervenir en el debate público, para denunciar las injusticias sociales y reivindicar la causa de los grupos subalternos, entre ellos los indígenas (Paz Soldán, 2006, p. 23). O como escribe Kowii, acciones como estas sirven para evitar "pulverizar las matrices culturales de nuestros pueblos", y "excluir la experiencia cultural de nuestros pueblos" por medio de referencias a lo indígena con un tinte negativo y doloso, cuyo efecto fue su desprestigio (2012, p. 2).

Consiguientemente, si se profundiza el estudio de los discursos de los movimientos indigenistas con la intención de comprender el por qué y qué es lo que demandan, conviene analizar previamente la literatura indigenista. Si por el contrario, se quiere estudiar los efectos de esta literatura en la sociedad, es útil comenzar por los discursos de los movimientos indigenistas. Por uno u otro camino se llega al mismo resultado: no hay posibilidad de satisfacer los reclamos indígenas sin una transformación significativa de la sociedad y del Estado. Por ello, es tan esencial dirigirse a criticar el orden constitucional, en la medida en que este asienta -en el plano legal- las desigualdades que se encuentran en la sociedad. 
Pero si lo que se busca es alguna diferencia relevante entre ambos tipos de relatos, esta se puede encontrar en el origen de quienes los construyen. Mientras los de los integrantes de la corriente literaria indianista son -por lo general- de miembros de la clase media local, y de alguna manera están emparentados con la clase dirigente, los de los movimientos indigenistas son producidos por ellos mismos. Es una diferencia relevante. En tanto la literatura solo expone la vida de los indígenas, y no se orienta primariamente a cambiar la sociedad sino solo a advertirle a esta cómo se vive en ella, por el contrario, los textos de los movimientos indigenistas se encaminan a superar sus propias condiciones de existencia por medio de la lucha, apelando a sus tradiciones ancestrales. No solo hay una diferencia de lenguaje, hay una distinción crucial de los horizontes de sentido que uno y otro da. Kowii indica con relación a esto lo siguiente:

Esta situación (la que instituyó la dominación que sufren los indígenas ecuatorianos) nos ayudó a comprender que nuestros pueblos, nuestros mayores han sido extremadamente fuertes, porque tuvieron dos misiones: una, construir la infraestructura civilizatoria de la sociedad occidental, y dos, mantener, conservar y cuidar la continuidad cultural de la civilización kichwa, de la civilización andina. Este escenario motivó a definir una posición política, a generar acciones, a plantearnos preguntas, a buscar respuestas que ayuden a comprender cuáles son las razones que han contribuido para que la piel, la conciencia, el subconsciente de nuestro pueblo, nuestra cultura siga vigente; cuáles son las matrices culturales que han influido, han actuado en este proceso de resistencia (2012, p. 3).

El puente construido entre la literatura indianista y los textos de los movimientos indigenistas generó lo que denominamos discurso contraconstitucional, cuyo fin principal es la transformación radical de la sociedad de modo de que los indígenas puedan tener los derechos que los blancos les han negado bajo el imperio de una ley injusta. Al proponerlo, los movimientos indigenistas siguieron los pasos de los sectores de izquierda de la Revolución Francesa. De ahí que algunos de los textos tengan una vinculación con aquellos de Robespierre y de Babeuf, germen de lo principal de las tesis marxistas, que también sirven de fuente para el discurso indigenista, cuya finalidad es la subversión del orden social y constitucional, a causa de las desigualdades y la situación de dominación que provoca en nombre de la civilización entre las comunidades indígenas,

¡Ñucanchic huasipungooo! Desde la capital, con la presteza con la cual las autoridades del Gobierno atienden estos casos, fueron enviados doscientos hombres de infantería a sofocar la rebelión. En los círculos sociales y gubernamentales la noticia circuló entre alarde de comentarios de indignación y órdenes heroicas: ¡Que se les mate sin piedad a semejantes bandidos!

Que se acabe con ellos como hicieron otros pueblos más civilizados.

Que se les elimine para tranquilidad de nuestros hogares cristianos. 
Hay que defender a las glorias nacionales... A don Alfonso Pereira, que hizo solo un carretero.

Hay que defender a las desinteresadas y civilizadoras empresas extranjeras (Icaza, 1972, p. 186).

Para comprender cómo nació este puente es conveniente partir de una perspectiva que no sea estrictamente legal. A tal fin, es apropiado tomar como marco de análisis la corriente Law and Literature. Nacida en los 80 en Estados Unidos, su intención fue estudiar el derecho a partir de reconocerle un valor explicativo significativo al entrecruzamiento entre la filosofía, el derecho y la literatura. Esto posibilitó la investigación del derecho desde un contexto más amplio que el proporcionado por la academia legal. ${ }^{2}$ Pero lo que interesa señalar es que ella hace saber a los operadores jurídicos un tema que los investigadores de la literatura ya habían notado: la literatura proporciona un punto de vista adecuado para el estudio del derecho, porque por su intermedio se conoce lo que la sociedad piensa y valora de sí misma y de su sistema legal. Si en las novelas indigenistas siempre se muestra una situación de menosprecio para con los indígenas, es porque -en términos generales- es lo que la sociedad piensa de ellos y de cómo deben ser tratados: "Los blancos, formados directamente por Dios, constituían una casta de hombres superiores y eran patrones; los indios, hechos

2 El movimiento Law and Literature parte - como expresa White- de la experiencia del abogado de enfrentar la realidad del cliente y de que el modo en que este último lo refiere — su dolor, su incertidumbre, su frustración, el sentido de la historia desde su punto de vista- no son fácilmente representados en el lenguaje del abogado, a causa de su distorsión o su pérdida de significado. De ahí que la literatura pueda ser el camino para la comprensión del mundo del cliente y el modo de imaginar la experiencia de otros (1998). con otra levadura y por manos menos perfectas, llevaban taras desde su origen y forzosamente debían de estar supeditados por aquéllos, siempre, eternamente... (Arguedas, 1972, p. 192).

Sin embargo, esto no debe llevar a sobrevalorar a la literatura en el examen de lo que es el derecho vivo. Más bien, lo que intenta decir la corriente Law and Literature es que -por medio de la literatura- quienes no son parte de los mundos que se relatan, pueden adentrarse en la vida de los otros, que es -en nuestro casocomo se conoce la vida de los indígenas en los Estados latinoamericanos. O como señalan algunos autores, a través de la literatura los operadores jurídicos pueden llegar a saber cómo es el mundo de sus clientes. Según Paz Soldán, esto significó para Arguedas preferir en sus relatos el uso del melodrama porque le permitía simplificar la confusión social en una maniquea lucha entre la virtud y el vicio, ante la cual era fácil adoptar una postura moral (2006, p. 19).

Empero, más allá de toda crítica acerca del valor de la corriente Law and Literature, lo que importa subrayar es que ella pone en conocimiento o visibiliza a los lectores -en el caso de la literatura indianista, o de otras semejanteslos reclamos de aquellos que conviven con nosotros, a quienes no se tiene en cuenta al elaborar las normas legales y al aplicarlas. Es lo que expresa uno de los personajes de El mundo es ancho y ajeno,

Desde Lima hasta el último rincón se extiende la nevada asfixiante. Puede faltar el pan, pero no el papel sellado. Es un mal nacional. Con có- 
digos y en papel sellado se ha escrito parte de la tragedia del Perú. La otra parte se ha escrito con fusiles y con sangre. ¡La ley, el sagrado imperio de la ley! ¡El orden, el sagrado imperio del orden! El pueblo, como un francotirador extraviado en la tierra de nadie, recibió ataques desde ambos lados y cayó abatido siempre (Alegría, 1973, p. 180).

Esto supone saltear las limitaciones que todo operador jurídico tiene por su origen social, su formación y su trabajo. Es lo que sostuvo -por ejemplo- el educador peruano Augusto Salazar Bondy en su diálogo Bartolomé o de la dominación (1974a). Si bien esta obra no puede propiamente ubicarse en el indigenismo literario, por su tema central -la lucha contra el colonialismo- ella tiene suficientes vinculaciones con esta literatura. En esta, el autor coloca en diálogo a cuatro personajes principales -Don Diego, el gobernador español; Bartolomé (presuponemos que es Bartolomé de las Casas); Hatuey, el cacique (quien puede entenderse como Ernesto Che Guevara, pues de acuerdo con lo dicho en la obra, Ernesto es su nombre de bautismo) y Frans (que parece ser Franz Fanon)-. En uno de los pasajes se hace decir a Hatuey lo siguiente: "Queremos que nos traten como a los cristianos y no nos repriman a sangre y fuego, matándonos como a perros, echando nuestros cuerpos a los campos para que se los coman los buitres, y que no asesinen a nuestras mujeres y a nuestros hijos en los pechos de sus madres (Salazar Bondy, 1974, p. 11).

Algo semejante se nota en la literatura indigenista boliviana, como lo muestra Jorge Icaza en su obra Huasipungo (1972):
Y fue entonces, cuando Chiliquinga, trepado aún sobre la tapia, crispó sus manos sobre el cuerno lleno de alaridos rebeldes, $y$, sintiendo con ansia clara e infinita el deseo y la urgencia de todos, inventó la palabra que podía orientar la furia reprimida durante siglos, la palabra que podía servirles de bandera y de ciega emoción. Gritó hasta enronquecer: iÑucanchic huasipungooo! (p. 184).

No muy diferente de lo que habla -en la realidad-el movimiento zapatista, para quien,

¿Y si nos vuelven a cerrar todas las puertas? ¿Y si la palabra no logra saltar los muros de la soberbia y de la incomprensión? ¿Y si la paz no es digna y verdadera, quién -preguntamosnos negará el sagrado derecho de vivir y morir como hombres y mujeres dignos y verdaderos? ¿Quién nos impedirá entonces vestirnos otra vez de guerra y muerte para caminar la historia? (Ejército Zapatista de Liberación Nacional, 1994, cit. en Ceceña, 2001, p. 12).

Lo que resaltan estos pasajes es lo que constituye uno de los elementos cruciales del indigenismo literario: la toma de conciencia de las condiciones de vida de los indígenas por parte de ellos mismos, hecho que justifica la emergencia de los movimientos indígenas como actores políticos. Aquí se da la reapropiación por parte de estos movimientos de su historia, que ya había sido dada a conocer por parte de la literatura indianista. Como escribe Alcides Arguedas en el prólogo a una de las ediciones de Raza de bronce, obra que le “ocupó los mejores momentos de vida, aquellos en que todo hombre de letras cree que ha nacido para algo muy serio y el escritor de tierras interiores y donde la 
pluma es lujo que no sustenta, tiene la candidez de imaginarse que puede producir algo que, por lo menos, tenga alguna duración en el tiempo..." (1972, p. 8).

Ese fruto que esperaba Arguedas que quizás podía producirse es el que se observa -tiempo después- en los eventos que conducen a las comunidades indígenas a convertirse en las productoras de su propio orden constitucional, que es lo que se percibe en las reformas constitucionales en Bolivia y Ecuador de los últimos años. Un fruto que no se satisface con la construcción de un orden constitucional alternativo, sino con la sustitución plena del vigente; si es necesario por medio de la violencia, la cual aunque no está favorecida de antemano, tampoco se la impide si ella se manifiesta. Es lo que se narra en el indigenismo literario, y que se encuentra también en las obras que relatan la Revolución Mexicana, por ejemplo, Los de abajo, de Mariano Azuela, donde el autor hace exclamar a uno de sus personajes: "nosotros no nos hemos levantado en armas para que un tal Carranza o un tal Villa lleguen a presidentes de la República; nosotros peleamos en defensa de los sagrados derechos del pueblo, pisoteados por el vil cacique (...)" (1973, p. 95).

En consecuencia, si algo contienen de valioso las obras del indigenismo literario son sus tramas, ya que por medio de ellas se puede apreciar la urgencia de modificar las injusticas y desigualdades que padecen las comunidades indígenas, y de esta manera hallar el modo de resolver los conflictos interétnicos que ellas describen.
Por último, en cuanto al plan de este trabajo, primero se analiza la intersección entre la literatura indigenista y la crítica al orden constitucional. Luego se examina el discurso contraconstitucional en términos generales, y en particular, cómo este conforma a las nuevas constituciones de Bolivia y Ecuador. Y se concluye con un estudio sobre las posibilidades de lo que el discurso contraconstitucional puede provocar -en términos legales- en la sociedad durante y a partir de la vigencia de sus nuevas constituciones. A tal fin se emplea una metodología exploratoria, y se realiza un examen crítico de las obras de sus principales exponentes literarios y del discurso que funda las reformas constitucionales boliviana y ecuatoriana.

\section{LA CRÍTICA AL ORDEN CONSTITUCIONAL}

La escritora Clorinda Matto de Turner coloca en el proemio a su obra Aves sin nido (1994) lo siguiente:

Si la historia es el espejo donde las generaciones por venir han de contemplar la imagen de las generaciones que fueron; la novela tiene que ser la fotografía que estereotipe los vicios y las virtudes de un pueblo, con la consiguiente moraleja correctiva para aquéllos y el homenaje de admiración para estos (p. 3).

Lo expuesto por la autora puede ser entendido como un adecuado punto de partida. La Constitución es la norma que idealmente une a las generaciones que la redactaron con aquellos a quienes se dirige, y van a vivir bajo su impe- 
rio. Aunque esta no pretende ser una fotografía como la novela, al igual que aquella contiene, como lo afirma Matto de Turner, "Ios vicios y las virtudes de un pueblo". Y es lo que la literatura indianista muestra.

La razón es que la literatura indigenista -como toda la literatura- expande y afina el sentido de lo político y lo ético de lo que se hace y se dice (White, 1998); porque "la obra literaria es un complejo intercambio de significaciones lingüísticas, en donde es importante tomar en cuenta la totalidad de la obra, en la que el autor ha puesto un sentido y una referencia totalizadoras" (Murillo, 2003, párr. 17).

Sin embargo, los investigadores advierten que la literatura no cumple una función de representación-reproducción -como usualmente se estima- sino que más bien es un sistema de textos en los cuales un grupo cultural se comprende y se relata a sí mismo. Por su intermediación se vislumbran las estructuras de dominación de una sociedad, su justificación y sus beneficiarios. Se muestra un mundo a partir de sus ausencias y sus deficiencias; un mundo cuyas prácticas sociales no son un reflejo de los modelos arquetípicos de conducta de una época histórica determinada, y en el que se manifiesta un proceso gradual de no identificación con los valores sociales dominantes.

Colocándose desde otro lugar, los autores descubren las deficiencias y las ausencias. O sea, aquello que las normas jurídicas no contemplan: las injusticias que conlleva su aplicación y ejecución, y la situación de los sujetos que las aceptan por coacción o porque no pueden impedir la presencia de un sistema legal que no los tiene bajo su protección, ya que para este aquellos no existen porque se encuentran invisibilizados, como indican los investigadores y lo expresan los autores indigenistas, o porque carecen de la unión y de la fuerza para desafiar ese orden.

Es lo que nota la obra de Arguedas Raza de bronce (1972), al narrar lo que se sigue de la violación y muerte de una mujer indígena por parte del hijo del dueño de la hacienda, y de sus amigos. Uno de los antiguos jefes de la comunidad hablando a quienes quieren rebelarse contra los blancos para vengar lo que estos han hecho, les dice lo siguiente:

De poco a esta parte, mis ojos se han cansado de ver tanta crueldad y tan grande injusticia, y a cada paso que doy en esta tierra me parece sentirla empapada con la sangre de nuestros iguales. Yo no me maravillo del rigor de los blancos. Tienen la fuerza y abusan, porque parece que es condición natural del hombre servirse de su poder más allá de sus necesidades. Lo que me lastima es saber que no tenemos a nadie para dolerse de nuestra miseria y que para buscar un poco de justicia tengamos que ser nuestros mismos jueces (...) (1972 p. 262).

Este pasaje sirve para distinguir dos momentos de la literatura indigenista. Siguiendo a Fell (1973) -y a otros investigadores- se diferencia entre un indigenismo romántico propio del siglo XIX, y un indigenismo reivindicatorio de los derechos del indígena en el siglo XX, que es el que nos importa destacar. Porque desde este 
último se tiende el puente al discurso contraconstitucional.

Continuando los pasos de la Revolución Francesa, el discurso contraconstitucional, al igual que el constitucionalismo que nace con aqueIla, se orienta a describir y subrayar la quiebra del antiguo orden constitucional y la necesidad de sentar un nuevo orden constitucional. Si ello es algo que realmente se ha dado en los países latinoamericanos cuyas constituciones tuvieron importantes reformas, es una cuestión sobre la cual los juristas no se han puesto de acuerdo. ${ }^{3}$ Aunque ello poco importa para quienes han decidido transformar sus órdenes constitucionales, por caso, los movimientos indigenistas.

Para los indígenas retratados en las novelas, sin una revuelta no hay un cambio significativo en sus vidas. El recuerdo del alzamiento de Túpac Katari en 1781 tiene el mismo sentido que la obtención de la independencia y de la libertad por parte de los esclavos en Haití. En ambos se da la presencia de un evento histórico paradigmático que conlleva, en uno, el intento de alterar el orden social dado, y en el otro, la transformación radical de la sociedad. Los dos relatos exponen que la violencia es un dato de importancia. Esto destaca algo que parece inevitable: la existencia previa de un hecho revolucionario.

La cuestión es que esto actualmente no es posible.

3 Para Viciano Pastor y Martínez Dalmau, "el nuevo constitucionalismo latinoamericano es un fenómeno surgido en el extrarradio de la academia, producto más de las reivindicaciones populares y de los movimientos sociales que de planteamientos teóricos coherentemente armados (...) consiguientemente, el nuevo constitucionalismo carece de una cohesión y una articulación como sistema cerrado de análisis y proposición de un modelo constitucional" (2011, p. 312).
Si hoy fuese propuesta una revolución para conseguir una reforma constitucional total, no habría lugar para su consideración dado que desde la mitad del siglo XX han surgido serios límites, por la inclusión en las constituciones de las normas emanadas de la protección internacional de los derechos humanos. ${ }^{4}$ Esos derechos constituyen una frontera que ningún Estado quiere - ni puede - traspasar, pero tampoco lo hace el discurso contraconstitucional ya que apela a ellos para justificar su nacimiento. Por consiguiente, con base en la consideración que se hace de los derechos humanos, no es extraño que se sostenga que las constituciones se han vuelto rígidas (Guastini, 2001, pp. 156, 189). Luego, una reforma total solo puede darse en el marco de una nueva legalidad.

Pero hay otro motivo que se puede añadir: la relación establecida entre Constitución y democracia, la que el discurso contraconstitucional no cuestiona, sino que más bien pone el acento en crear una democracia horizontal y participativa, según las palabras del movimiento zapatista. Con esto se pretende obtener aquello que el orden constitucional vigente no brinda: derechos e igualdad materiales a partir de un concepto amplio de ciudadanía, que es lo que han buscado los movimientos indigenistas, y que la literatura indianista mostró solo como revueltas locales, sin incidencias en un plano mayor.

\footnotetext{
4 En este punto, por ejemplo, la Constitución boliviana asienta en el art. 410.II.: "La Constitución es la norma suprema del ordenamiento jurídico boliviano y goza de primacía frente a cualquier otra disposición normativa. El bloque de constitucionalidad está integrado por los Tratados y Convenios internacionales en materia de Derechos Humanos y las normas de Derecho Comunitario, ratificados por el país".
} 
¿Significa que estos discursos -el literario y el indianista - crean un ambiente favorable a provocar una revolución? No, aunque quienes lo enuncian no pueden evitar tenerla en cuenta, pues se piensa: ¿de qué otro modo se puede establecer una Constitución que sea verdaderamente democrática? Si la Constitución expone la estratificación social, sin un cambio completo del modo de ser de esta no es posible una transformación correlativa en el orden constitucional. Por consiguiente, se torna necesario realizar una transformación social de cierta magnitud,

En las contradicciones y tensiones se develan los problemas que afligen a una colectividad, se visibilizan las diferentes propuestas de solución de los problemas, y en las conflictividades mismas, develadas por esas contradicciones, es donde la sociedad articula proyectos, alianzas y medios para solucionarlas, parcial o plenamente. Tensiones y contradicciones son por tanto los mecanismos mediante los cuales se logran los cambios y se impulsa el avance de una sociedad, y forman parte indisoluble del curso democrático y revolucionario de los pueblos (García Linera, 2011, p. 25).

De ahí que para el discurso contraconstitucional la justicia y la igualdad fundamenten la demanda central por la reivindicación de los derechos de los indígenas. En este punto, el diseño constitucional se convierte en un tema crucial, ya que los fines y los valores que los movimientos indigenistas tengan en mira van a constituir los principios supraconstitucionales de la nueva Constitución. No solo se pone en juego su aceptación por toda la sociedad, sino también sus condiciones de realización. Con referencia a esto Kowii dice:
En lo personal considero que la interculturalidad debe ser construida bajo la base de derechos y obligaciones, es decir, reconocer efectivamente el derecho histórico de los pueblos indios de ser pueblos, culturas diferentes; de hacer conciencia de que en un espacio en el cual coexisten pueblos y lenguas diferentes, es necesario, es indispensable que las sociedades que coexisten, que comparten el mismo espacio, el mismo territorio, deben asumir el reto, la obligación de aprender mutuamente la lengua del otro, deben aprender a valorarse y respetarse (2012, p. 11).

A fin de comprender lo que los movimientos indigenistas han puesto en juego al intervenir decididamente en el proceso de construcción constitucional, es útil considerar, en primer lugar, que, por ejemplo, en Bolivia, el antiguo marxismo no es significativo ni política ni intelectualmente, y el marxismo crítico, proveniente de una nueva generación intelectual, tiene una influencia reducida y círculos de producción aún limitados (García Linera, 2009, p. 477). Por lo tanto, si bien pueden hallarse puntos en común entre la literatura indianista, el discurso de los movimientos indigenistas y el marxismo, esto no conduce a ubicar a estos movimientos ni a las constituciones surgidas de su acción política como de inspiración marxista.

Primero, el marxismo es para ellos también una doctrina europeísta y occidental. Y en segundo lugar, ambos discursos -el literario y el de los movimientos indigenistas-se dirigen a desafiar -con diferente magnitud e interés-dos conceptos clave del orden constitucional, los de estatalidad y de ciudadanía. Por eso, el indigenismo 
literario antecede a la construcción del discurso del indigenismo político.

Esto nos conduce a Meadows (1960), para quien hay un elemento subjetivo en los movimientos sociales: Ios valores frustrados en la vida cotidiana, entre ellos, la justicia y la igualdad, que se pretenden instaurar o recuperar. En cierta manera, con las nuevas constituciones boliviana y ecuatoriana se intenta retornar a un orden constitucional originario, donde se plenifiquen la justicia y la igualdad, que es lo que afirma Babeuf, "es necesario pues, que las instituciones sociales nos lleven a un punto en el que nieguen a todo individuo ser más rico, más potente y más distinguido que ninguno de sus iguales" (1970, p. 137), donde "nadie (tiene) privilegios, ni un individuo, ni una clase de individuos pequeña o grande" (Büchner, 1997, p. 89), o como expresa uno de los personajes de Arguedas:

No tengo fe en nadie y menos en nuestros doctores inflados con discursos muy orondos con su palabrería hueca, muy metidos en lecturas de libritos extranjeros, pero sin ojos para ver lo que nos falta, sin carácter para osar emprender para moverse. Estamos en poder de los doctores cholos, que todo lo quieren hacer con discursos; que se dan por modelos de decencia, patriotismo y honradez, y que en la vida privada se muestran egoístas, tacaños, sucios moral y materialmente... (1972, p. 204).

Hay en esto una pugna entre -al menos- dos concepciones de justicia, una lucha que se resuelve comúnmente en favor de los poderosos, y donde se resalta el rol del derecho penal para mantener el statu quo, y otra justicia que emer- ge fuera de los tribunales, y que coloca en tensión al orden social existente. Se afirma que la ley debe cumplirse aun si ella tiene consecuencias injustas. Esto presupone que las personas quedan libradas a las decisiones de la Providencia, y deben ser aceptadas por funestas que ellas sean,

Pero lo que no me explico todavía es por qué los propietarios no intentan algo por mejorar la suerte del indio, para hacer de él un aliado y no un siervo. Yo conozco el estado social de Rusia, que tantos lamentos provoca en el mundo por el estado de abyección y servidumbre en que vive el mujik; pero te aseguro que su condición es mil veces más feliz y ventajosa que la del pobre indio del yermo. La miseria del indio no tiene igual en el mundo, porque es miseria de miserable, en tanto que la del ruso es solo miseria de hombre, susceptible a veces de cambiar. La del indio no cambia nunca. Siervo nace y de siervo muere... (Arguedas, 1972, p. 210).

Esto produce desconfianza hacia los poderes constituidos y hacia quienes los ejercen. Se manifiesta la necesidad de un cambio que pase por restaurar el poder constituyente originario, sin el cual no parece factible un nuevo orden constitucional, y tampoco un verdadero orden democrático, como el que aspiraba conseguir la conspiración de los iguales de Babeuf. Como advierte Kowii,

Este proceso debe estar acompañado de acciones previas o paralelas, debe estar acompañado de acciones de democratización, de sensibilización, de humanización de la población. En este sentido es indispensable extirpar de la idiosincrasia de la población latinoamericana 
el racismo que el sistema colonial y republicano logró sembrar en las conciencias de nuestras poblaciones. Este es el principal reto. No hacerlo, significará forzar a los pueblos originarios a que recurran a la violencia en defensa de su integridad, de su derecho a la lengua, a la cultura, a la vida (2012, p. 11).

Por consiguiente, la worship of the Constitution de la cual habla Corwin (1928) cae frente al law in action, porque al mostrar la literatura indigenista primero, y los discursos de los movimientos indigenistas después, las contradicciones entre lo que la Constitución ordena y lo que sucede en la realidad, la Constitución deja de ser un texto legal rígido y perenne, que debe respetarse tout court. Porque como afirman los movimientos indigenistas, las normas jurídicas han sido elaboradas para mantener el statu quo social, es decir, los privilegios de un determinado estamento o clase, ${ }^{5}$

Porque el blanco, desde hace más de cuatrocientos años, no ha hecho otra cosa que vivir del indio, explotándolo, robándole, agotando en su servicio su sangre y su sudor. Y si el indio le odia, siente desconfianza hacia él y hace todo lo humanamente posible para causarle males, es que con la leche, por herencia, sabe a su vez que el blanco es su enemigo natural y como a enemigo le trata. Esto, convendrás, es justo y muy humano (Arguedas, 1972, p. 208).
Con base en esto, la violencia con la cual -a veces- han sido impuestos esos órdenes constitucionales repercute y condiciona la respuesta de quienes lo desafían. Pero esto se puede entender desde otra perspectiva.

El conflicto se da en las sociedades boliviana y ecuatoriana por estar regidas por constituciones oligárquicas, refleja - de alguna maneralas antiguas luchas en la antigua Grecia y en Roma. Esto tiene sentido cuando - siguiendo a Pisarello (2011) - se vuelve al análisis del orden constitucional, partiendo de la antigua distinción entre constituciones oligárquicas y constituciones democráticas.

Al igual que en la Antigüedad clásica, la denuncia del viejo orden constitucional comporta no solamente la pérdida de autoridad de la clase dirigente, sino también la correlativa pérdida de sentido de la estratificación social. Por eso, “La revolución beneficia al pobre, al ignorante, al que toda su vida ha sido esclavo, a los infelices que ni siquiera saben que si lo son es porque el rico convierte en oro las lágrimas, el sudor y la sangre de los pobres" (Azuela, 1973, p. 27). Y es lo que el discurso contraconstitucional busca revertir del modo que sea.

\section{EL DISCURSO CONTRACONSTITUCIONAL}

\section{A. Notas generales}

5 "la justicia, en tanto gran organización estatal, es un subcentro de Poder social: aquí se aplican normas sobre las cuales se basa la concepción de un orden intacto; el comportamiento de las personas es sancionado positiva o negativamente de acuerdo a la conformidad o desviación de estas normas; de esta manera, se conservan y refuerzan privilegios y desventajas ya existentes" (Lautmann, 1984, p. 82).

\footnotetext{
En la novela clásica de Azuela sobre la Revolución Mexicana uno de los personajes dice lo siguiente,
} 
Somos elementos de un gran movimiento social que tiene que concluir por el engrandecimiento de nuestra patria. Somos instrumentos del destino para la reivindicación de los derechos sagrados del pueblo. No peleamos por derrocar a un asesino miserable, sino a la tiranía misma. Eso es lo que se llama luchar por principios, tener ideales (1973, p. 45).

El pasaje contiene notas interesantes para hacer una genealogía del discurso contraconstitucional. En primer lugar, se rescata el rol de algunos movimientos sociales en la génesis de este discurso. Siguiendo a Meadows (1960), concordamos con el autor en que estos nacen en períodos de crisis, exteriorizando una situación de insatisfacción respecto de las instituciones existentes. Se manifiesta el fracaso de un sistema institucional, dice este investigador, que coloca a algunos movimientos sociales ante la necesidad de construir un cambio social profundo; ${ }^{6}$ de "orientar la furia reprimida durante siglos", Io cual implica la destrucción -y uso esta palabra deliberadamente- del sistema constitucional vigente, porque "La revolución es el huracán, y el hombre que se entrega a ella no es ya el hombre, es la miserable hoja seca arrebatada por el vendaval" (Azuela, 1973, p. 63). Por eso, es esencial "dar un salto decisivo, el salto que lleva de la conciencia liberal a la conciencia libertaria, nervio de la revolución" (Salazar Bondy, 1974a, p. 56).

Segundo, hay una "reivindicación de los derechos sagrados del pueblo", frase que se con-

6 La intención de determinados movimientos sociales es - a veces-el apartamiento de la sociedad, por eso no se puede sostener que todos los movimientos sociales busquen una reforma radical de la sociedad. vierte en una constante a partir de la Revolución Francesa, y que es el motivo fundamental de los movimientos indigenistas para actuar contra los órdenes social y constitucional establecidos, a los que ven como productos de la dominación efectuada por los conquistadores. Por eso, Carpentier hace decir a unos de sus personajes - Ti Noel- en su novela que trata sobre la independencia de Haití, que la victoria sobre los amos blancos realiza el sueño de andar sobre "una tierra en que la esclavitud había sido abolida para siempre" (1978, p. 83). Es lo que Robespierre, citado en Sanguinetti (1972), acentúa cuando exclama que un gobierno revolucionario se apoya en la más sagrada de las leyes: la salvación del pueblo; en el más irrefutable de los títulos: la necesidad (p. 121). Y es lo que aparece en las revueltas indígenas en Bolivia y Ecuador narradas por Arguedas e Icaza respectivamente. El peso de tal juicio es tan esencial que se lo formula en el preámbulo de la Constitución boliviana,

El pueblo boliviano, de composición plural, desde la profundidad de la historia, inspirado en las luchas del pasado, en la sublevación indígena anticolonial, en la independencia, en las luchas populares de liberación, en las marchas indígenas, sociales y sindicales, en las guerras del agua y de octubre, en las luchas por la tierra y territorio, y con la memoria de nuestros mártires, construimos un nuevo Estado.

Un tema que se expresa con igual tenor en el preámbulo de la Constitución ecuatoriana:

Como herederos de las luchas sociales de liberación frente a todas las formas de dominación 
y colonialismo,

Y con un profundo compromiso con el presente y el futuro,

Decidimos construir

Una nueva forma de convivencia ciudadana, en diversidad y armonía con la naturaleza, para alcanzar el buen vivir, el sumak kawsay;

Una sociedad que respeta, en todas sus dimensiones, la dignidad de las personas y las colectividades...

Tercero, se exterioriza una revuelta contra la dominación del blanco pero también la del mestizo,

¿Qué nuevas iniquidades ha cometido el mestizo? -preguntó Choquehuanka tras largo silencio.

Todos los días hace algo. Se ha cansado de matar patos y ahora ha emprendido con las gallinas y los perros, y muchos han tenido que llevar sus bestias a las haciendas vecinas o encerrarlas en las habitaciones.

¿Y siempre se muestra duro con la gente?

Ayer le rompió la cabeza por dos partes a Leque, pegó a Cheka y le hizo voltear con su caballo a Condori, que iba a la feria de Chililaya (Arguedas, 1972, p. 248).

La revolución no se dirige contra una persona determinada -aunque se la nombre- sino contra el modo de ser de la autoridad política, contra la jerarquía social existente, de la cual es reflejo el orden constitucional. Porque "la legitimidad viene por el modo de ejercer el mando y no por el origen (...) el poder se legitima por sus hechos; cuando ayuda al hombre, suprime totalmente la opresión y la persigue hasta sus raíces, es legítimo" (Salazar Bondy, 1974, p. 78). A esto se dirige el indianismo, "el indianismo, poco a poco, se ha ido constituyendo en una narrativa de resistencia que en estos últimos tiempos se propuso como una auténtica opción de poder" (García Linera, 2009, p. 477).

Por último, se destaca que es una lucha por principios. Esto define que la finalidad es la instauración de un nuevo orden social y legal, que es lo que afirma Robespierre: “la República solo cuenta con las virtudes. Y las virtudes son simples, modestas, pobres, con frecuencia ignorantes, a veces groseras; son la dote de los desposeídos y el patrimonio del pueblo" (Robespierre, 1972, p. 125). Porque “¡Pueblo sin ideales, pueblo de tiranos!" (Azuela, 1973, p. 73); "solo un pluralismo de vías de acción permitirá batir al enemigo en todos los terrenos y construir una nueva humanidad realmente creadora y libre" (Salazar Bondy, 1974a, p. 64). En esta línea se debe entender lo que fija la Constitución ecuatoriana en su art. 416.8. “(se) reconoce el derecho de los pueblos a la resistencia y liberación de toda forma de opresión".

\section{B. Notas para caracterizar al discurso contraconstitucional}

El camino que conduce al discurso contraconstitucional pasa por asentar la distinción que existe entre un orden revolucionario y un orden constitucional. Mientras el primero se halla libre de ataduras de todo tipo, pues nada impide el 
uso de la violencia, sino que se la alienta en determinadas circunstancias, "la guerra es justa y necesaria cuando es guerra de liberación" dice un personaje del diálogo escrito por Salazar Bondy (1974a, p. 38); el segundo queda delimitado por las normas constitucionales creadas para proteger las libertades y los derechos civiles, pues como Robespierre sostiene: no puede haber una Constitución hasta que se dé la victoria sobre los enemigos de la libertad (citado en Sanguinetti, 1972, p. 120). De ahí, lo imprescindible que es mantener a la ciudadanía en un estado de vigilancia permanente, una cuestión que se expresa en el art. 26.I. de la Constitución boliviana:

Todas las ciudadanas y los ciudadanos tienen derecho a participar libremente en la formación, ejercicio y control del poder político, directamente o por medio de sus representantes, y de manera individual o colectiva. La participación será equitativa y en igualdad de condiciones entre hombres y mujeres.

Uno de cuyos antecedentes podría ser la redacción del art. 9 de la Constitución francesa de 1793, que indica: "la ley debe proteger la libertad pública e individual contra la opresión de aquellos que gobiernan". La vigilancia permanente de los ciudadanos de la tarea asignada a quienes integran los poderes constituidos es el fundamento para sostener que el estado revolucionario no cesa, sino que permanece en suspenso.

Segundo, la secuencia que lleva de un régimen a otro, por la cual, no hay una reforma total si ella no está precedida de una revolución, su- giere que -tal vez- las nuevas constituciones boliviana y ecuatoriana pueden ser observadas como el fruto de la acción revolucionaria de los movimientos indigenistas, especialmente en el caso de Bolivia si se consideran las guerras del agua y del gas. ${ }^{7}$ Por eso, Meadows opina que

la base objetiva de los movimientos sociales se encuentra en todos los factores que contribuyen a la aparición de la situación crítica. La crisis es el medio para el desarrollo abundante de los movimientos. Todos los movimientos sociales son funciones de situaciones críticas (1960, p. 39).

Tercero, en este discurso hay una contraposición entre los vicios de la antigua clase dirigente y las virtudes que tienen las nuevas. Se presenta la búsqueda de una justicia y una igualdad absolutas, tal como expresa un revolucionario mexicano en la novela de Azuela, cuando brindó

por el triunfo de nuestra causa, que es el triunfo sublime de la Justicia; porque pronto veamos

7 La Guerra del agua se desarrolló entre 1997 y 2000, como consecuencia de la acción del consorcio transnacional Aguas del Tunari en el departamento de Cochabamba, realizada bajo el amparo de la Ley 2029 por la cual aquel obtuvo el manejo del agua potable y el alcantarillado sanitario, para cuya realización se introdujo la indexación de las tarifas que abrió el camino a la dolarización de las tarifas del agua. Esto condujo a la lucha por lo que se denominó "la política de las necesidades básicas o de sobrevivencia". El nivel de tensión que apareció con la ejecución del contrato llevó al presidente Banzer a declarar el estado de sitio. Al final los concesionarios perdieron el monopolio y la dolarización de tarifas fue eliminada. Se restauró la calma en Cochabamba, y el 20 de abril se levantó el estado de sitio, y Banzer pidió disculpas por cualquier error cometido (Kruse, 2005).

En cuanto a la Guerra del gas — de acuerdo con Prada Alcoreza (2003) - involucró y unió a todos los sectores sociales que participaron en los movimientos sociales desde el 2000. La consigna fue la defensa del gas como punto de partida de la lucha contra la globalización privatizadora, la ejecución de las políticas neoliberales, el ajuste estructural, y las consecuencias de dichas reformas. Por eso, se planteó el conflicto como una recuperación de la soberanía nacional frente al nuevo orden mundial. Se buscó no solo recuperar los recursos naturales sino también el excedente. 
realizados los ideales de redención de este nuestro pueblo sufrido y noble, y sean ahora los mismos hombres que han regado con su propia sangre la tierra los que cosechen los frutos que legítimamente les pertenecen (1973, p. 61).

Cuarto, frente a esto, los límites legales caen; "hay una nueva política de legalidad e ilegalidad. Las nuevas resistencias son muy pragmáticas, utilizan la legalidad que está a su disposición, pero también medios ilegales. Hay una forma de utilizar la ilegalidad que puede ser totalmente pacífica, pero no está en el marco del derecho oficial" (Santos, 2007, p. 18). Es lo que reclama Babeuf (1970): el cese de las instituciones humanicidas y su reemplazo por instituciones plebeyas. Esto lleva a algunos autores a afirmar la presencia de un nacionalismo plebeyo, que -en el fondo- es una vinculación entre lo concebido por los revolucionarios franceses y lo proclamado por los movimientos indigenistas que estimamos no es un producto del azar.

Estimo que lo expuesto sirve para describir el discurso contraconstitucional. Y es lo que los relatos del indigenismo literario narran: la ley no protege a quienes más la necesitan o la reclaman, solo los poderosos gozan de su protección. El rico o el fuerte pueden torcer el fin del derecho, colocándose por encima de la norma. A los débiles y a los pobres no les queda otro camino que cumplir con el derecho. Como asegura uno de los personajes de la obra Huasipungo: "Los indios... ¿Qué nos importan los indios? Mejor dicho... Deben... Deben importarnos... Claro... Ellos pueden ser un factor importantísimo en la empresa. Los brazos... El trabajo..." (Icaza, 1972, p. 12). Ni aquellos que son los modelos para la sociedad las cumplen,

El religioso echó su cabeza sobre el respaldo del asiento donde descansaba para hundirse en una pausa un poco teatral. Debía asegurar los sucres de su comisión en el negocio. El dinero estaba muy cerca de sus manos. Hasta Dios dice: "Agárrate que yo te agarraré... Defiéndete que yo defenderé...” ¡Ah! Con tal de no agarrarse de los espinos y de las alimañas de los chaparros del viejo Isidro, estaba salvado (Icaza, 1972, p. 30).

Por eso, el valor de estos textos - entonces- viene dado no solo por ser retratos de lo que sucede sino por mostrar cómo es el ambiente en el que - de alguna manera- se forma la mentalidad democrático-revolucionaria, y da contenido al discurso contraconstitucional.

\section{EL CAMINO HACIA LA DEMOCRACIA REVOLUCIONARIA}

La lucha contra quienes se estima que son los principales beneficiarios de un constitucionalismo antidemocrático y oligárquico tiene contemporáneamente - según los discursos de los movimientos indigenistas- a dos principales contendientes: el imperialismo, entendiendo por tal el norteamericano, y el neoliberalismo. Esto no excluye la crítica a las élites coloniales internas, pues ellas colaboran en el sostenimiento -dentro de los Estados- de las estructuras de dominación. 
Del éxito de esa confrontación depende la refundación del Estado, y la reasunción de la soberanía por parte de los ciudadanos, o sea, la vuelta al poder constituyente originario; un retorno imprescindible para convertir a las constituciones en instrumentos para desafiar a las estructuras de dominación, sea por los derechos que se reconocen, ${ }^{8}$ los sujetos que se visibilizan, ${ }^{9}$ o por el nivel de estatalidad que se fija. ${ }^{10}$

La reforma constitucional total emerge como la principal consecuencia de la transformación social. Para Viciano Pastor y Martínez Dalmau con esto “[se] reivindica el carácter revolucionario del constitucionalismo democrático, dotándolo de los mecanismos actuales que pueden hacerlo más útil en la emancipación y avance de los pueblos a través de la Constitución como mandato directo del poder constituyente" (2011, p. 312). Por eso, para las asambleas constituyentes no es un problema ni el cómo de la reforma constitucional ni los límites que esta deba tener.

8 La Constitución de Ecuador expresa en el Capítulo Primero referido a los Derechos, en el art. 10, que "la naturaleza será sujeto de aquellos derechos que le reconozca la Constitución".

9 El Capítulo Tercero de la Constitución ecuatoriana, referido a los Derechos de las personas y grupos de atención prioritaria, en el art. 35 dice: "Las personas adultas mayores, niñas, niños y adolescentes, mujeres embarazadas, personas con discapacidad, personas privadas de libertad y quienes adolezcan de enfermedades catastróficas o de alta complejidad, recibirán atención prioritaria y especializada en los ámbitos público y privado. La misma atención prioritaria recibirán las personas en situación de riesgo, las víctimas de violencia doméstica y sexual, maltrato infantil, desastres naturales o antropogénicos. El Estado prestará especial protección a las personas en condición de doble vulnerabilidad".

10 La Constitución boliviana fija en el art. 91 que son fines y funciones esenciales del Estado, además de los que establece la Constitución y la ley, entre otros, el de "constituir una sociedad justa y armoniosa, cimentada en la descolonización, sin discriminación ni explotación, con plena justicia social, para consolidar las identidades plurinacionales".
Frente al positivismo jurídico se alza un derecho alternativo que busca sentar otras bases para el funcionamiento de la sociedad. Es lo que pretenden algunos movimientos sociales: una democracia revolucionaria que les permita recobrar la isonomía real, cuyo resultado sea la recuperación por parte de los ciudadanos invisibilizados de los derechos y las libertades que les han sido negados o limitados indebidamente.

Esto lleva a repensar la validez del poder simbólico de la Constitución dado por la modernidad, "No se tiene otra opción de democratización superior del Estado que no sea la del reconocimiento de múltiples formas plurales de democracia (directa, representativa, comunitaria) y de desconcentración territorial del poder a través de las autonomías" (García Linera, 2011, p. 10).

Empero, así como una Constitución puede ser un medio para afianzar un régimen despótico o antidemocrático, también puede ser el instrumento para consolidar un tipo de sociedad diferente. Esto funda la necesidad de elaborar un derecho alternativo, una respuesta regional a las mistificaciones que se hicieron de la Constitución al amparo de la academia legal y de las necesidades de las élites locales afines al imperialismo. Se manifiesta la quiebra del viejo constitucionalismo conservador, y la emergencia de un constitucionalismo emancipador. En la medida que

Desde las constituciones fundacionales latinoamericanas -que, por otro lado, fueron más cercanas al liberalismo conservador que al revolucionario- América Latina había carecido 
de procesos constituyentes ortodoxos -esto es, plenamente democráticos- y, en cambio, había experimentado en multitud de ocasiones procesos constituyentes representativos de las élites y alejados de la naturaleza soberana esencial del poder constituyente (...). En general, las constituciones del viejo constitucionalismo no cumplieron más que los objetivos que habían determinado las élites: la organización del poder del Estado y el mantenimiento, en algunos casos, de los elementos básicos de un sistema democrático formal (Viciano Pastor y Martínez Dalmau, 2011, p. 315).

Se presenta un modo alternativo de construir el derecho como sucede, por ejemplo, con los movimientos indígenas, el Movimiento de los Trabajadores Rurales Sin Tierra de Brasil, los zapatistas en México o los movimientos indigenistas en Bolivia ${ }^{11}$ y Ecuador,

La vida es sinónimo de lucha sumada a contradicción, y en el caso de nuestra revolución, las clases populares, su vanguardia indígenacampesina-obrera y vecinal es la condensación viviente de esas contradicciones, de esas luchas, cuyo producto será su auto-emancipación. Comprenderlas y articularlas como un flujo de voluntad de poder común, comunista, capaz de remontar a cada paso las iniciativas de las clases pudientes y conservadoras, es la tarea del Gobierno de los Movimientos Sociales (García Linera, 2011, p. 74).

11 "En Bolivia, el proceso constituyente no se inicia con la instalación de la Asamblea Constituyente el 6 de agosto pasado, sino que nace en los momentos de insurrección colectiva, en los diferentes ciclos de movilización social, que fueron en sí mismos momentos de disputa por el sentido de lo político. Fueron los momentos de insurrección popular en los que se modificó el escenario político, creando las condiciones de posibilidad para la refundación del Estado" (Chávez y Mokrani, 2007, p. 107).
En este sentido, son -principalmente- los movimientos indigenistas quienes encaran el proceso de desmontar la cultura europea, en un sentido amplio, y los estereotipos y la marginalización que se han hecho de lo no europeo. Aquí se da un proceso denominado ruptura epistemológica que incorpora como elementos cruciales: la memoria, la subjetividad y la variable cultural, para demoler la razón única proveniente de la modernidad (Tórrez, 2006-2007, p. 104). En este proceso se exterioriza un movimiento de recuperación de lo originario que es un efecto del proceso de descolonización ${ }^{12}$ que alienta el discurso contraconstitucional, y que señala la necesidad de construir una sociedad postcolonial. ${ }^{13}$

A tal fin adquieren relevancia en la redacción constitucional palabras como descolonización, antiesencialismo $^{14}$ y emancipación, nociones

12 La descolonización es un proceso que implica un desmarque de la situación colonial —en un sentido amplio- en el cual se encuentran diversos Estados, especialmente aquellos del Tercer Mundo. Conlleva la emergencia de una pluriversalidad colonial frente a la universalidad imperial, dice Mignolo (1996). Para Walsh (2008) es parte de una lucha, de una resistencia de los pueblos históricamente subalternizados.

13 "El término postcolonial es una expresión ambigua, algunas veces peligrosa, otras veces confusa, generalmente limitada y empleada inconscientemente. Es ambigua cuando se la utiliza para aludir a situaciones socio-históricas relacionadas con la expansión colonial y la descolonización a través del tiempo y del espacio (...) Por consiguiente, el término "postcolonialidad" o "lo postcolonial" se vuelve problemático cuando se aplica a las prácticas culturales tanto del siglo XIX como a las del siglo XX" (Mignolo, 1996, p. 99).

14 El antiesencialismo junto con el antirrepresentacionismo "son rasgos que caracterizan el pragmatismo rortyano y que se traducen en la invitación a dejar atrás el pathos de la epistemología, denominador común en la tradición filosófica, que nos instalaría en la pretensión de que nosotros, seres condicionados, podemos desplegar nuestra existencia o nuestro conocimiento de acuerdo a algo incondicionado, llámese 'esencia invariable de las cosas', 'ley natural', 'estructura última de la racionalidad o del lenguaje', 'naturaleza humana', o de cualquier otro modo. Esta pretensión estaría destinada a verificar permanentemente la imposibilidad de su satisfacción, porque no podemos escapar de la contingencia de todo discurso humano, de la contextualidad en que estamos situados o nos hemos formado, ni de la finitud de nuestra propia razón" (Figueroa, 2005, p. 138). 
comprensibles a la luz de las teorías jurídicas críticas, pero también bajo la literatura indianista.

Según Wolkmer, si se manifiesta una revisión crítica del derecho dominante -en nuestro caso, del derecho constitucional vigente en Latinoamérica- es porque existe una crisis de legitimidad y una crisis de producción y aplicación de la justicia, que ha generado un movimiento transcontinental de crítica de forma heterogénea y no sistemática, comprensivo de múltiples tendencias, corrientes y formulaciones surgidas de matrices ideológicas y científicas distintas, que reflejan las condiciones sociopolíticas que predominan en sus países de origen (2003, p. 45). Se reclama

una reformulación de la democracia. Una democracia no solamente representativa, sino una democracia participativa, comunitaria; una democracia mucho más amplia, basada en el diálogo, en el consenso, en la revocatoria y fiscalización permanentes. Hablamos de la profundización de esa democracia con el contingente de otros pueblos, y por eso es importante esa diversidad para poder hacer que en este país se exprese la existencia del Otro (Macas, 2005, p. 38).

Porque como afirma Robespierre, los constituyentes tienden a aislarse rápidamente de sus mandantes, les esconden las razones de sus decisiones y buscan apartarlos de los asuntos públicos (citado por Mathiez, 1989).

La democracia revolucionaria quita el monopolio para construir el derecho que detentan los juristas y los políticos tradicionales, y expone el papel de los movimientos sociales en la producción de normas legales así como el peso que han logrado los foros sociales como espacios de debate prelegal, como construcción de un espacio altermundialista. Por eso, Santos escribe que

A partir de Chiapas y Seattle, el movimiento global contra el neoliberalismo adquirió un nuevo nivel de conciencia colectiva con el primer Foro Social Mundial en Porto Alegre, en enero de 2001. Se trata de un nuevo tipo de movimiento que simbólicamente marca una ruptura con las formas de organización de las clases populares vigentes durante el siglo XX. Es un movimiento muy heterogéneo en términos de base social en el que (...) dominan las organizaciones de trabajadores, aunque no se presenten como tales (...) Su lema común - «otro mundo es posible»- revela la misma heterogeneidad e inclusividad (2012, p. 136).

La democracia revolucionaria es, por consiguiente, el paso previo a la reformulación global de la Constitución vigente y del sistema legal regional. Y es el motor del discurso contraconstitucional.

IV. ¿SON LAS NUEVAS CONSTITUCIONES LATINOAMERICANAS FRUTO DEL DISCURSO CONTRACONSTITUCIONAL?

La respuesta sobre si las nuevas constituciones latinoamericanas son el fruto del discurso contraconstitucional puede partir de lo sostenido en el preámbulo tanto de la Constitución boli- 
viana como de la Constitución ecuatoriana, para las cuales hay un pueblo soberano que lucha desde los tiempos de la independencia por ser reconocido como tal, que se halla compuesto de "mujeres y hombres de distintos pueblos", que apela a la "memoria de los mártires", en orden a erigir un nuevo Estado, libre de "todas las formas de dominación y colonialismo".

Esto presupone reconocer previamente que con la independencia de las naciones latinoamericanas no cesó de existir una suerte de colonialismo -interno y externo- que en vez de tener como sujeto activo a España, tuvo a Inglaterra y ahora tiene a Estados Unidos como poderes dominantes. Por eso, se acentúa el tema de la soberanía en los textos constitucionales. ${ }^{15}$ Con la ruptura con el antiguo orden constitucional se obtiene la recuperación del poder constituyente originario, y se puede lograr un nuevo orden constitucional.

A diferencia de lo sucedido en la Revolución Francesa, la liberación hoy es obra de los pueblos, los movimientos sociales -en nuestro caso, los indigenistas- quienes se convierten en los nuevos sujetos colectivos de la historia. Es lo que enuncia -por ejemplo- la Constitución boliviana.

Con esta redacción se busca enfatizar la toma de posición contrahegemónica que pretenden Bolivia y Ecuador. Porque al ser la nueva Constitución el producto legal de la toma del poder

15 La Constitución ecuatoriana habla — por ejemplo — de soberanía del pueblo (art. 1); soberanía alimentaria (Capítulo Tercero); soberanía energética (art. 15); soberanía territorial (art. 158); soberanía económica (Capítulo Cuarto); y soberanía sobre la biodiversidad (art. 400). político, ella es la formulación legal del inicio de la descolonización lograda. ${ }^{16}$

Esto importa en el caso boliviano: revisar las relaciones entre el Estado y las inversiones extranjeras; los vínculos entre el Estado y las regiones; el reconocimiento de la diversidad de las identidades sociales -en especial, las étnicas-, y la mutación de las pautas de participación y representación político-institucionales (Mayorga, 2006, p. 8).

Pero además hay un rescate de las culturas ancestrales que marca el comienzo de la sociedad postcolonial. En este sentido, se dice que el fin supremo es refundar la República, y establecer una sociedad democrática, participativa y protagónica, multiétnica y pluricultural. Esto lleva a pensar la Constitución como un discurso emancipador, que en términos generales no parece ser una novedad.

Empero, a medida que se profundiza el examen de la construcción de una sociedad postcolonial, su desarrollo tiene una lectura adecuada desde la perspectiva del discurso contraconstitucional. Frente a la dependencia cultural, se alza un poder constituyente originario, que no es un "poder constituyente de la multitud", sino "una instancia de "constitucionalización" de los cambios en marcha, como la recuperación de los recursos naturales. En este sentido está presente la experiencia venezolana: transformar la actual iniciativa política de la izquierda naciona-

16 En el caso venezolano la reforma constitucional sirve para instaurar lo que se denomina socialismo bolivariano o socialismo del siglo XXI. 
lista en una hegemonía de largo aliento" (Stefanoni, 2006, p. 39).

En suma, la respuesta a si este constitucionalismo latinoamericano es el producto del discurso contraconstitucional es afirmativa. Por eso, no es posible examinar estos procesos partiendo de los cánones deducidos de una doctrina legal elaborada por una academia afín a las élites dominantes, porque el tema de fondo es el ejercicio del poder contra o a favor de las estructuras de dominación existentes. De ahí la conveniencia de partir de la literatura indianista, la que sin tecnicismos legales, describe las razones para sostener la necesidad de transformar radicalmente la sociedad.

Por consiguiente, es posible afirmar que el indigenismo se expresa en nuestra época a través de la construcción constitucional boliviana y ecuatoriana, un producto híbrido, propio de las culturas que han conformado a América Latina. A consecuencia de lo cual no faltan elementos de diversas fuentes: las ideológicas derivadas del jacobinismo y del girondismo, las teológicas nacidas del cristianismo, las marxistas y las propiamente indigenistas. De esta mezcla surge un discurso cuya finalidad es transformar la sociedad por medio de la liberación de toda dependencia -en un sentido amplio-, la construcción de un nuevo orden social fundado en las nociones de justicia e igualdad, y la instauración de una convivencia humana que manifieste una vida armónica entre los seres humanos, y de estos con la naturaleza.

El resultado de esto es la introducción en el lenguaje constitucional de los principios del buen vivir, que como señala el preámbulo de la Constitución ecuatoriana es "una nueva forma de convivencia ciudadana, en diversidad y armonía con la naturaleza, para alcanzar el buen vivir, el sumak kawsay. Una sociedad que respeta, en todas sus dimensiones, la dignidad de las personas y las colectividades", siendo el equivalente de esto en la Constitución boliviana el suma qamaña. De acuerdo con Ariruma Kowii, esta

Es una concepción andina ancestral de la vida que se ha mantenido vigente en muchas comunidades indígenas hasta la actualidad. Sumak significa lo ideal, lo hermoso, lo bueno, la realización; y kawsay, es la vida, en referencia a una vida digna, en armonía y equilibrio con el universo y el ser humano, en síntesis el sumak kawsay significa la plenitud de la vida (s. f., p. 5).

Como expresa este mismo autor, se debe tener en cuenta que en los mitos fundacionales del pueblo kichwa ocupa un lugar destacado la pareja, mujer-hombre, en las personas, en las montañas, en los objetos; una dualidad vigente en la cotidianidad y en los rituales que se realizan para la sanación. Su presencia indica -prosigue este autor- el mensaje de estar, avanzar juntos, estar presente, con lo cual refrenda la importancia del concepto de complementariedad, equilibrio y equidad,

El Buen Vivir, en definitiva, tiene que ver con otra forma de vida, con una serie de derechos y garantías sociales, económicas y ambientales. También está plasmado en los principios orientadores del régimen económico, que se caracterizan por promover una relación armoniosa entre los seres humanos individual y colecti- 
vamente, así como con la Naturaleza (Acosta, 2008, p. 38).

Esto se asegura, además, por medio del reconocimiento de cada etnia de la que se compone cada Estado -Bolivia y Ecuador-. La intención es subrayar la diferencia, no para separar sino para afirmarla en la vida social y en la conformación del nuevo Estado. ${ }^{17}$ Por ejemplo, en Bolivia

el discurso de Evo Morales recupera los códigos del nacionalismo revolucionario, con un cambio en el sujeto revolucionario: ya no es "el pueblo" como alianza de clases y sectores sociales (como en el discurso del Movimiento Nacionalista Revolucionario en 1952), sino un conglomerado de identidades y movimientos sociales con predominio de lo étnico, los "pueblos indígenas", quienes son interpelados como sujetos de un proyecto de reconfiguración de la comunidad política que ya no es concebida como "una nación" sino como una articulación de "naciones originarias" (Mayorga, 2006, p. 10).

Para Santiváñez Vivanco "aunque parezca mentira, reconocer la herencia indígena ha supuesto, para Latinoamérica, un proceso de introspección intelectual tan desgarrador como doloroso y una batalla política en la que el populismo, como era de esperar, ha salido triunfante" (2010, p. 142).

17 Advierte Quijano que en el caso peruano la mayor parte de la población que es considerada india o indígena no está incorporada, ni parece interesada en estarlo, a ningún movimiento indígena de las dimensiones e impacto que se da en otros países. Para este investigador, la razón de esto es el proceso de desindianización que se manifestó con la urbanización de la sociedad, la crisis del Estado oligárquico y la bancarrota de sus principales expresiones de dominación cultural (2006, p. 18).
Esto requiere de una ética que fundamente la justicia y la igualdad, los principios supraconstitucionales del nuevo sistema legal. La formulación de esta implica la crítica de la ética de quienes son las élites dominantes, que es lo que aparece en la obra de Arguedas aunque sin la fuerza del discurso que tendrán los movimientos indigenistas. Un ejemplo de esto aparece en el art. 8.I. de la Constitución boliviana:

El Estado asume y promueve como principios ético-morales de la sociedad plural: ama qhilla, ama llulla, ama suwa (no seas flojo, no seas mentiroso ni seas ladrón), suma qamaña (vivir bien), ñandereko (vida armoniosa), teko kavi (vida buena), ivi maraei (tierra sin mal) y qhapaj ñan (camino o vida noble)

Esta situación lleva a que Wolkmer indique que “la edificación de un pensamiento crítico latinoamericano (que) no implica la total negación o la ruptura radical con otras formas racionales de conocimiento heredadas del iluminismo y producidas por la modernidad europea o norteamericana, pero sí un proceso dialéctico de asimilación, transposición y reinvención" (2003, p. 85).

El último paso de este proceso de reconversión de la sociedad se da a través del establecimiento de una sociedad en armonía con la naturaleza. Se sostiene que lo realmente novedoso no es la introducción de nuevos elementos, sino el intento de construir nuevas lógicas y formas de conocer, pensar, ser y vivir bajo parámetros radicalmente distintos (Walsh, 2008, p. 150). Habiendo recuperado el constitucionalismo boliviano y ecuatoriano un carácter emancipador por medio del ejercicio de una democracia revo- 
Iucionaria, los movimientos indigenistas logran la redacción de una Constitución radicalmente democrática, que es la finalidad última del discurso contraconstitucional. Ahora bien, ¿en qué medida, es posible afianzar los puntos sustentados en este discurso por medio de las nuevas constituciones?

\section{CONCLUSIONES}

La muerte de la monarquía y el nacimiento de la república es la secuencia que marca y distingue a la Revolución Francesa de otras semejantes. Las medidas tomadas por los revolucionarios tienen por meta: asegurar en todos los aspectos de la vida social lo ganado en la guerra contra los enemigos internos y externos de la Revolución. Para ello, se juzga necesaria la implantación de una dictadura, y para algunos, del Terror. Por cierto, hoy no aparecen estos temas como indispensables para establecer un nuevo orden constitucional. Con todo, una cosa es clara, a fin de edificar el nuevo orden constitucional se requiere un periodo mayor de tiempo de gobierno que el previsto en la mayor parte de los sistemas constitucionales comparados. Estando la reelección presidencial limitada, si se quiere llevar adelante una reforma social junto con una reforma constitucional plena, es ineludible pensar que los periodos presidenciales previstos en las constituciones vigentes no alcanzan para lograrlo.

Esto plantea una controversia de magnitud que se soluciona, o partiendo de una nueva legalidad, o extendiendo al máximo la existente. Es decir, o se toma un poder constituyente originario en estado de permanente actividad y vigilancia, siguiendo el modelo revolucionario francés, hasta tanto no exista un tiempo de paz para que pueda afirmarse la Constitución definitiva, y se admite la presencia de una autoridad política ilimitada en el tiempo, que es la solución de Robespierre, o por el contrario, se intenta extender la reelección presidencial hasta el límite de lo permitido legalmente, que es la solución que adoptan los presidentes surgidos por la aplicación de las nuevas constituciones.

Sin embargo, lo que queda claro para la sociedad es que no hay posibilidad de fijar un nuevo orden social, y subsiguientemente, una nueva Constitución, con autoridades políticas limitadas por la norma legal. Por un lado, las reformas constitucionales apuntan a una reconceptualización de la noción de Estado, que no es susceptible de lograrse en el mediano plazo. Igual ocurre con la transformación social expuesta en el discurso contraconstitucional.

La complejidad de fundar un nuevo orden social tampoco se obtiene en el mediano plazo. El reconocimiento legal de la interculturalidad conlleva el gobierno de esta, una cuestión que no se revela sencilla en la práctica. Para ponerla en ejercicio es imprescindible considerar un asunto que es exclusivamente de orden gnoseológico: la ruptura epistémica.

La reelaboración del lugar del conocimiento, de sus contenidos, así como del lugar desde donde se enuncia, implica la aceptación de otras lógicas, de otros saberes - en este caso, los ances- 
trales, es decir, los provenientes de los pueblos indígenas- que como señala Walsh, conlleva el vivir según otros parámetros (2008). Es por este punto por donde comienza el cambio y justifica lo que el discurso contraconstitucional pretende.

Estamos ante una nueva sociedad cuya génesis cercana puede datarse de la conmemoración de los 500 años de la conquista española, un acontecimiento que sirvió para visibilizar los reclamos indígenas y denunciar el carácter racista de la construcción de las naciones latinoamericanas; una movilización que se fortaleció en Ecuador y en Bolivia (Benavides Vanegas, 2010, p. 246).

El nuevo Estado es plurinacional, fundado en una política del reconocimiento y en la construcción de una democracia no asimilacionista, que permite la toma de decisiones colectivas a través del diálogo y el consenso, en vez de la regla de la mayoría propia de las democracias liberales (Benavides Vanegas, 2010, p. 255).

Si bien se pueden mencionar otros problemas, estimo que estos bastan para mostrar que los fines del discurso contraconstitucional se agotan a medida que la revolución deja paso a las nuevas instituciones. Por lo cual, este discurso es útil solo si se dirige a cambiar radicalmente la sociedad y, por ende, el derecho, ya que al modificar la estratificación social puede correlativamente alterar el proceso de construcción constitucional. Una democracia horizontal permite un ejercicio de la soberanía pleno, haciendo realmente de cada individuo un verdadero legislador. Si ello es posible de mantener a lo largo de las décadas, no es nuestra tarea predecirlo. Solo basta señalar la importancia que tienen estas constituciones como expresión del discurso contraconstitucional.

\section{Referencias}

Acosta, A. (2008). El Buen Vivir, una oportunidad por construir. Ecuador debate (75), 3348. Recuperado de: http://www.ecuadordebate.com/wp-content/uploads/2010/06/ Ecuador-debate-75.pdf

Alegría, C. (1973). El mundo es ancho y ajeno. (Cuarta edición). Buenos Aires: Losada.

Arguedas, A. (1972). Raza de bronce. (Quinta edición). Buenos Aires: Losada.

Arguedas, A. (2006). Raza de bronce. Caracas: Biblioteca Ayacucho. Prólogo, cronología y bibliografía de José Edmundo Paz Soldán.

Azuela, M. (1973). Los de abajo. México: Fondo de Cultura Económica.

Babeuf, F. N. (1970). Realismo y utopía en la Revolución Francesa. (M. Tarragó, Trad.). BarceIona: Península.

Benavides Vanegas, F. S. (Enero-Abril de 2010). Movimientos indígenas y Estado plurinacional en América Latina. Pensamiento Jurídico, (27), 239-264.

Bolivia. Constitución Política del Estado. (Febrero de 2009). Recuperado de: http://www. 
gacetaoficialdebolivia.gob.bo/edicions/view/ NCPE

Carpentier, A. (1978). El reino de este mundo. (Séptima ed.). Barcelona: Seix Barral.

Ceceña, A. E. (Junio de 2001). La marcha de la dignidad indígena. OSAL, Observatorio Social de América Latina, 9-14. Recuperado de: http://biblioteca.clacso.edu.ar/ar/libros/ osal/osal4/analisis.pdf

Constitución de la República Bolivariana de Venezuela. (2009). Recuperado de: http:// www.cgr.gob.ve/contenido.php?Cod=048

Constitución de la República del Ecuador. (2008). Recuperado de: http://www.utelvt. edu.ec/NuevaConstitucion.pdf

Corwin, E. S. (December of 1928). The "Higher Law" Background of American Constitutional Law. Harvard Law Review, (42), 149-185.

Chávez, P. y Mokrani, D. (Septiembre de 2007). Los movimientos sociales en la Asamblea Constituyente. Hacia la reconfiguración de la política. OSAL, Observatorio Social de América Latina, VIII(22), 107-117. Recuperado de: http://biblioteca.clacso.edu.ar/ar/libros/ osal/osal22/AC22ChavezMokrani.pdf

Fell, È-M. (1973). Les indiens. Societés et idéologies en Amérique Hispanique. Paris: Armand Colin.

Figueroa, M. (2005). Cultura y dominación masculina: aportes críticos de E. Dussel y R. Ror- ty. Persona y Sociedad. Universidad Alberto Hurtado, XIX(2), 131-142. Recuperado de: http://www.personaysociedad.cl/wp-content/uploads/2011/04/figeroa.pdf

García Linera, Á. (2009). La potencia plebeya. Acción colectiva e identidades indígenas, obreras y populares en Bolivia. Bogotá: Siglo del Hombre y CLACSO.

García Linera, Á. (2011). Las tensiones creativas de la revolución: la quinta fase del Proceso de Cambio. La Paz, Bolivia: Vicepresidencia del Estado Plurinacional-Presidencia de la Asamblea Legislativa Plurinacional.

Guastini, R. (2001). Estudios de teoría constitucional. México: Universidad Nacional Autónoma de México e Instituto de Investigaciones Jurídicas.

Guastini, R. (Julio de 2013). A propósito del neoconstitucionalismo. Gaceta Constitucional, (67), 231-240.

Icaza, J. (1972). Huasipungo. (Octava ed.). Buenos Aires: Losada.

Kowii, A. (s. f.). El Sumak Kawsay. Recuperado de: http://www.un.org/esa/socdev/unpfii/ documents/El\%20Sumak\%20Kawsay-ArirumaKowii.pdf

Kowii, A. (2012). Literatura e interculturalidad: la expresión creativa y crítica de las voces de las nacionalidades y pueblos del Abya-Yala y sus retos en los Estados Nacionales de América Latina - El caso ecuatoriano. Quito: Uni- 
versidad Andina Simón Bolívar. Recuperado de: http://www.uasb.edu.ec/UserFiles/372/ File/pdfs/PAPER\% 20UNIVERSITARIO/ Ariruma\% 20Kowii\% 20\%5BLiteratura\% 20 e\%20interculturalidad\%5D\%281\%29.pdf

Kruse, Th. (2005). La "Guerra del Agua" en Cochabamba, Bolivia: terrenos complejos, convergencias nuevas. En E. de la Garza Toledo (Comp.). Sindicatos y nuevos movimientos sociales en América Latina (págs. 121-161). Buenos Aires: Consejo Latinoamericano de Ciencias Sociales. Recuperado de: http://biblioteca.clacso.edu. ar/subida/uploads/FTP-test/clacso/gt/ uploads/20101109025721/5kruse.pdf

Lautmann, R. (1984). Sociología y jurisprudencia. Buenos Aires: Sur.

Macas, L. (2005). La necesidad política de una reconstrucción epistémica de los saberes ancestrales. En P. Dávalos (Comp.). Pueblos indígenas, Estado y democracia (págs. 3542). Buenos Aires: Consejo Latinoamericano de Ciencias Sociales. Recuperado de: http://bibliotecavirtual.clacso.org.ar/clacso/ gt/20101026124724/3Macas.pdf

Mathiez, A. (1989). Robespierre el incorruptible. Estudios históricos. (J. C. Martell, Trad.). Montevideo: Nuevo Mundo.

Mayorga, F. (Noviembre-Diciembre de 2006). El gobierno de Evo Morales: entre nacionalismo e indigenismo. Nueva Sociedad, (206),
4-13. Recuperado de: http://www.nuso.org/ upload/articulos/3390_1.pdf

Meadows, P. (1960). Marco para el estudio de los movimientos sociales. (Á. M. Montiel, Trad.). México: Biblioteca de Ensayos Sociológicos, Instituto de Investigaciones Sociales, Universidad Nacional Autónoma de México.

Mignolo, W. (1996). Herencias coloniales y teorías postcoloniales. En B. González Stephan, Cultura y tercer mundo: cambios en el saber académico (págs. 99-136). Caracas: Nueva Sociedad.

Murillo, D. (Junio-Julio de 2003). Semiótica y creación literaria. Razón y palabra (33), 1-7. Recuperado de: http://www.razonypalabra. org.mx/anteriores/n33/dmurillo.html

Paz Soldán, J. E. (2006). Prólogo, cronología y bibliografía. En A. Arguedas, Raza de bronce. Caracas. Biblioteca Ayacucho.

Pisarello, G. (2011). Un largo Termidor: la ofensiva del constitucionalismo antidemocrático. Madrid: Editorial Trotta.

Prada Alcoreza, R. (Septiembre-Noviembre de 2003). Perfiles del movimiento social contemporáneo. El conflicto social y político en Bolivia. Las jornadas de septiembre-octubre de 2003. OSAL. Observatorio Social de América Latina, IV(12), 35-46. Recuperado de: http:// bvsde.org.ni/clacso/publicaciones/OSAL12. pdf 
Quijano, A. (Enero-Abril de 2006). Estado-nación y movimientos indígenas en la región Andina: cuestiones abiertas. OSAL. Observatorio Social de América Latina, VI(19), 15-24. Recuperado de: http://biblioteca.clacso.edu.ar/ clacso/osal/20110327050057/02Quijan. pdf

Salazar Bondy, A. (1974b). Filosofía de la dominación y filosofía de la liberación. En A. Salazar Bondy, América Latina: filosofía y liberación. Simposio de filosofía latinoamericana (págs. 153-157). Buenos Aires: Bonum.

Salazar Bondy, A. (1974a). Bartolomé o de la dominación. Buenos Aires: Ciencia Nueva.

Sanguinetti, H. (1972). Robespierre. La razón del pueblo. (H. Sanguinetti, Trad.) Buenos Aires: La Bastilla.

Santiváñez Vivanco, M. (Abril-Junio de 2010). Inkarrí: indigenismo y socialismo del siglo XXI. Cuadernos de pensamiento político, 26 (págs.141-170). Recuperado de: http://www. fundacionfaes.org/file_upload/publication/ pdf/20130423215044inkarri-indigenismo-ysocialismo-del-siglo-xxi.pdf

Santos, B. de S. (Marzo 26 de 2007). Reinventando la emancipación social. En Pensar el Estado y la sociedad: desafíos actuales (págs. 13-35). Buenos Aires: Waldhuter Editores. Recuperado de: http://bibliotecavirtual. clacso.org.ar/ar/libros/coedicion/boavent/ cap\%201.pdf
Santos, B. de S. (Abril de 2012). De las dualidades a las ecologías. La Paz, Bolivia: Red Boliviana de Mujeres Transformando la Economía.

Stefanoni, P. (Enero-Abril de 2006). El nacionalismo indígena en el poder. En OSAL. Observatorio Social de América Latina, VI(19), 3744. Recuperado de http://bibliotecavirtual. clacso.org.ar/ar/libros/osal/osal19/stefanoni.pdf

Tórrez, Y. (Semestre II de 2006 y semestre I de 2007). Vuelta de tuerca: insurgencia política y epistémica de los movimientos sociales en Bolivia. Comentario Internacional (7), 93107. Recuperado de: http://repositorio.uasb. edu.ec/bitstream/10644/2044/1/Cl-07-TCT\%C3\%B3rrez.pdfTÓRREZ

Turner, C. M. de. (1994). Aves sin nido. Caracas: Biblioteca Ayacucho.

Viciano Pastor, R. y Martínez Dalmau, R. (Diciembre de 2011). Fundamentos teóricos y prácticos del nuevo constitucionalismo latinoamericano. Gaceta Constitucional, (48), 307-328. Recuperado de: http://www.gacetaconstitucional.com.pe/sumario-cons/docsum/GC\%2048\%20\%20Roberto\%20VICIANO\%20y\%20Ruben\%2OMARTINEZ.pdf

Walsh, C. (Julio-Diciembre de 2008). Interculturalidad, plurinacionalidad y decolonialidad: las insurgencias político-epistémicas de refundar el Estado. Tabula Rasa, (9), 131-152. 
Recuperado de: http://www.scielo.org.co/ pdf/tara/n9/n9a09.pdf

White, J. B. (Winter, 1998). What we know. Cardozo Studies in Law and Literature X(2), 151153.
Wolkmer, A. C. (2003). Introducción al pensamiento jurídico crítico. Bogotá: Colección en Clave de Sur-ILSA. Recuperado de: http:// ilsa.org.co:81/biblioteca/dwnlds/eclvs/eclvs04/eclvs04-01-03.pdf 